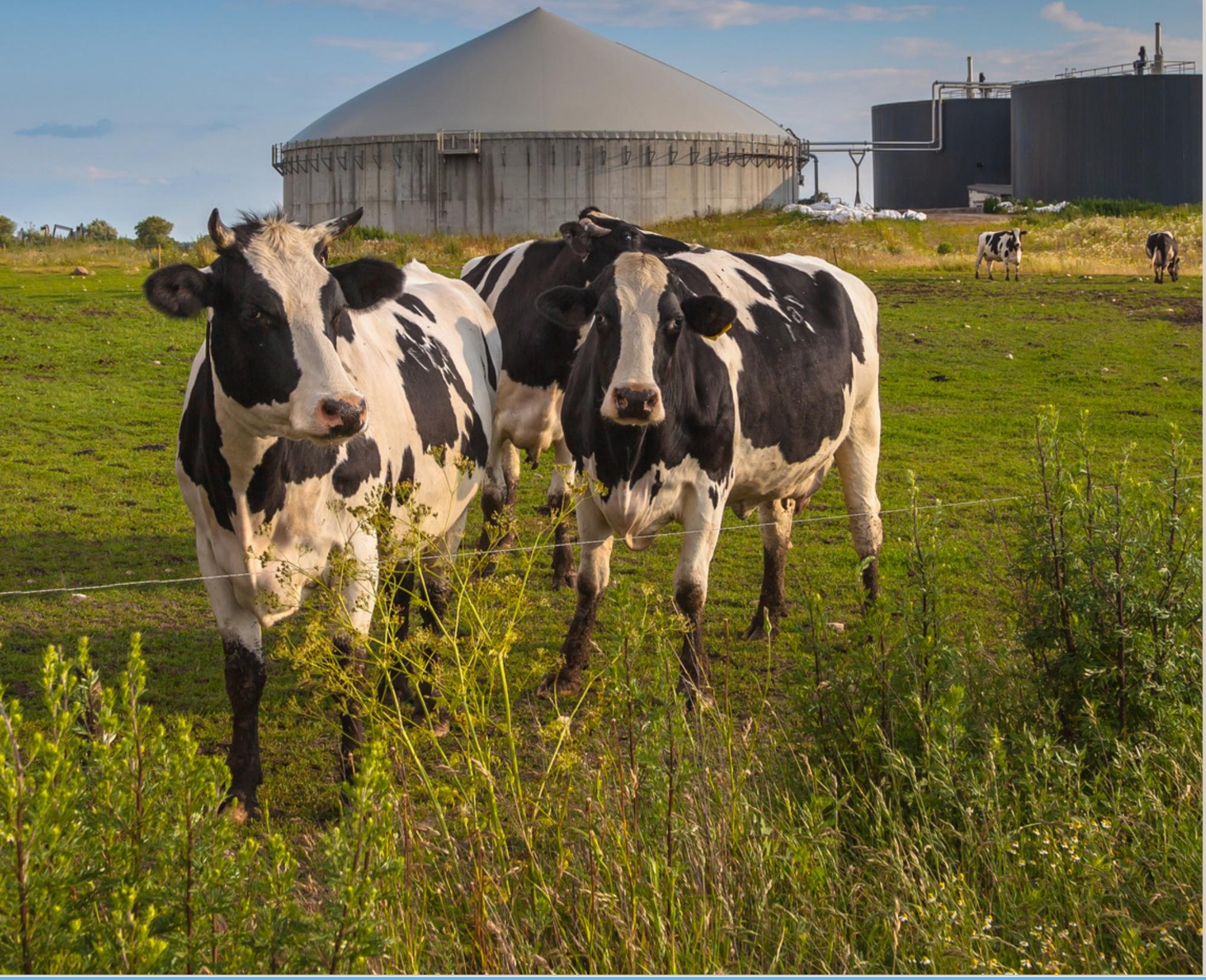

Effect van vergisting op het orthofosfaat gehalte in rundermest en potentieel voor terugwinning 



\section{Effect van vergisting op het orthofosfaat gehalte in rundermest en potentieel voor terugwinning}

M. Timmerman, H.C. de Boer, N. Verdoes, H. Schilder

Wageningen Livestock Research

Dit onderzoek is uitgevoerd door Wageningen Livestock Research, en gefinancierd door het Melkveefonds.

Wageningen Livestock Research

Wageningen, Maart 2018

Rapport 1088 

Timmerman, M., H.C. de Boer, N. Verdoes, H. Schilder, 2018. Effect van vergisting op het orthofosfaat gehalte in rundermest en potentieel voor terugwinning. Wageningen Livestock Research, Rapport 1088.

Samenvatting NL In dit rapport zijn de resultaten beschreven van het onderzoek naar het effect van vergisting op het orthofosfaat-gehalte in rundermest. Op verschillende melkveebedrijven met een mestvergister en mestscheider zijn monsters genomen van de drijfmest, het digestaat, dunne fractie, dikke fractie en geanalyseerd op de gehalten aan orthofosfaat. Aanvullend is orthofosfaat uit de dunne fracties geprecipiteerd m.b.v. calciumhydroxide. Het orthofosfaat gehalte neemt af door vergisting. Het orthofosfaat gehalte lag in het digestaat op gemiddeld $34 \mathrm{mg} / \mathrm{kg}$ en was lager dan in de ingaande drijfmest met een gemiddeld gehalte van $75 \mathrm{mg} / \mathrm{kg}$

Summary UK This report describes the results of the research into the effect of anaerobic digestion on the orthophosphate content in dairy manure. On different dairy farms with a manure digester and separators samples were taken from the manure, digestate, liquid fraction, thick fraction and analyzed on the content of orthophosphate. Furthermore, the orthophosphate was extracted from the liquid fraction with calcium hydroxide. The orthophosphate content decreases as a result of anaerobic digestion. The orthophosphate content was on average $34 \mathrm{mg} / \mathrm{kg}$ in the digestate and was lower than in the incoming manure with average content of $75 \mathrm{mg} / \mathrm{kg}$.

Dit rapport is gratis te downloaden op https://doi.org/10.18174/442316 of op www.wur.nl/livestock-research (onder Wageningen Livestock Research publicaties).

\section{(C) 2018 Wageningen Livestock Research}

Postbus 338, 6700 AH Wageningen, T 03174839 53, E info.livestockresearch@wur.nl, www. wur. nl/livestock-research. Wageningen Livestock Research is onderdeel van Wageningen University \& Research.

Wageningen Livestock Research aanvaardt geen aansprakelijkheid voor eventuele schade voortvloeiend uit het gebruik van de resultaten van dit onderzoek of de toepassing van de adviezen.

Alle rechten voorbehouden. Niets uit deze uitgave mag worden vermenigvuldigd en/of openbaar gemaakt worden door middel van druk, fotokopie, microfilm of op welke wijze dan ook zonder voorafgaande toestemming van de uitgever of auteur.

De certificering volgens ISO 9001 door DNV onderstreept ons kwaliteitsniveau. Op als onze onderzoeksopdrachten zijn de Algemene Voorwaarden van de Animal Sciences Group van toepassing. Deze zijn gedeponeerd bij de Arrondissementsrechtbank Zwolle. 



\section{Inhoud}

$\begin{array}{ll}\text { Samenvatting } & 5\end{array}$

$\begin{array}{lll}1 & \text { Inleiding } & 7\end{array}$

$\begin{array}{lll}1.1 & \text { Achtergrond } & 7\end{array}$

$\begin{array}{lll}1.2 & \text { Doel } & 7\end{array}$

$\begin{array}{lll}1.3 & \text { Afbakening } & 7\end{array}$

2

$\begin{array}{ll}\text { Materiaal en Methode } & 8\end{array}$

2.1 Mestverzameling $\quad 8$

2.2 Bemonstering mestsoorten 9

2.2.1 Bedrijf $1 \quad 9$

2.2.2 Bedrijf $2 \quad 9$

2.2.3 Bedrijf $3 \quad 9$

2.2.4 Bedrijf $4 \quad 9$

2.3 Mestanalyses 10

$\begin{array}{lll}2.4 & \text { Restgasbepaling } & 10\end{array}$

$\begin{array}{lll}2.5 & \text { Terugwinning van fosfaat uit de dunne fractie } & 11\end{array}$

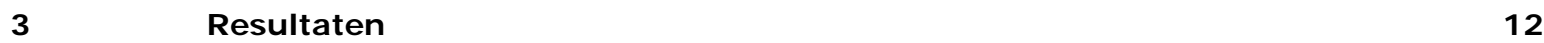

$\begin{array}{lll}3.1 & \text { Invloed opslagduur } & 12\end{array}$

$\begin{array}{lll}3.2 & \text { Effect van vergisting en vergistingsduur } & 13\end{array}$

$\begin{array}{lll}3.3 & \text { Effect van scheiding op orthofosfaat } & 16\end{array}$

$\begin{array}{lll}3.4 & \text { Terugwinning van orthofosfaat uit de dunne fractie } & 18\end{array}$

4 Discussie $r \begin{aligned} & 19\end{aligned}$

$5 \quad$ Conclusies $\quad 20$

$\begin{array}{ll}\text { Literatuur } & \mathbf{2 1}\end{array}$

$\begin{array}{lll}\text { Bijlage } 1 & \text { Resultaten restgasbepaling } & 22\end{array}$ 



\section{Samenvatting}

Bij vergisten wordt een deel van de organische stof afgebroken en de verwachting is dat organisch gebonden fosfaat dan in de vorm van orthofosfaat beschikbaar zou kunnen komen. Vergisting zou het daarmee makkelijker kunnen maken om fosfaat uit dierlijke mest terug te winnen. Er is nog weinig kennis over de kwaliteit van fosfaat bij het vergisten van mest. Daarom is onderzoek uitgevoerd naar het effect van vergisting op het orthofosfaat-gehalte in rundermest.

Op een viertal melkveebedrijven met een vergister waarvan drie met een scheider zijn (gescheiden) mest en (gescheiden) digestaat verzameld en geanalyseerd op het gehalte aan orthofosfaat. Verder is in een batchexperiment getracht de orthofosfaat uit de dunne fractie te winnen door middel van dosering van calciumhydroxide $\left(\mathrm{Ca}(\mathrm{OH})_{2}\right)$ aan de dunne fractie.

Het uitgevoerde verkennende onderzoek heeft de volgende resultaten opgeleverd:

- Verse mest had met gemiddeld $107 \mathrm{mg} / \mathrm{kg}$ het hoogste orthofosfaat gehalte en hoe langer de mest in opslag bleef hoe lager het orthofosfaat gehalte werd.

- Het orthofosfaat gehalte neemt af door vergisting. Het orthofosfaat gehalte lag in het digestaat op gemiddeld $34 \mathrm{mg} / \mathrm{kg}$ en was lager dan in de ingaande drijfmest met een gemiddeld gehalte van $75 \mathrm{mg} / \mathrm{kg}$.

- $\quad$ Bij toenemende verblijftijd daalde het orthofosfaat gehalte in het digestaat, van 59 naar 39 $\mathrm{mg} / \mathrm{kg}$.

- In de dunne fracties varieerde het orthofosfaat gehalte van 13 tot $41 \mathrm{mg} / \mathrm{kg}$, en was gelijk of lager dan het orthofosfaat gehalte in de ingaande digestaat of drijfmest. Het aandeel orthofosfaat van het totaal fosfaat lag in de dunne fracties wel hoger dan in ingaande digestaat of drijfmest.

- Hoe hoger de $\mathrm{pH}$ hoe lager het gehalte aan orthofosfaat bleek te zijn in de onderzochte mestsoorten.

- Het orthofosfaat gehalte in het digestaat van vergiste rundermest, dunne en dikke fracties digestaat was niet hoog genoeg om dit te gaan winnen uit digestaat en gescheiden fracties zonder aanvullende maatregelen, zoals aanzuren om meer orthofosfaat vrij te maken uit de aanwezige minerale fosfaatverbindingen. 


\section{$1 \quad$ Inleiding}

\subsection{Achtergrond}

In de akkerbouw is er behoefte aan organische meststoffen van hoge kwaliteit. Voornamelijk meststoffen met een hoog organische stof gehalte en een laag fosfaatgehalte zijn gewenst. Het hoge organische stofgehalte is gewenst vanwege behoud en opbouw van de bodemvruchtbaarheid. Het lage fosfaatgehalte is gewenst naast een goede stikstof-fosfaat-verhouding, omdat akkerbouwers per kg aan te wenden fosfaat uit dierlijke mest zoveel mogelijk organische stof willen aanvoeren. Echter dierlijke meststoffen met veel organische stof en laag fosfaatgehalte zijn op dit moment niet beschikbaar uit de huidige mestverwerkingssystemen.

Bij vergisten wordt een deel van de organische stof afgebroken en daarmee zou er meer fosfaatverbindingen afgebroken kunnen worden tot orthofosfaat. Vergisting zou het daarmee makkelijker kunnen maken om fosfaat uit dierlijke mest terug te winnen. Verder leven er vragen in de praktijk of de afbraak van de organische stof in de vergister wel wenselijk is en niet ten koste gaat van de bodemvruchtbaarheid. Anderzijds wordt gesteld dat in een vergister alleen de gemakkelijk afbreekbare organische stof wordt afgebroken. Deze organische stof zou toch vervluchtigen in de mestopslag en/of na het aanwenden van de mest. De organische stof opbouw in de bodem zou dan vooral afhankelijk zijn van de moeilijk afbreekbare organische stof. Er is dus behoefte aan kennis over de kwaliteit van fosfaat en de organische stof bij het vergisten van mest.

\subsection{Doel}

Het doel van het onderzoek was het bepalen van het effect van vergisting op het orthofosfaat gehalte in rundermest, dunne en dikke fractie rundermest.

\subsection{Afbakening}

In deze rapportage wordt het onderzoek naar het effect van vergisting op het orthofosfaat gehalte beschreven. De bepaling van het effect van vergisting op de bodemvruchtbaarheid (opbouw organische stof) wanneer digestaat wordt aangewend als meststof i.p.v. onvergiste mest staat beschreven in De Boer et al. (2018). 


\section{Materiaal en Methode}

\section{$2.1 \quad$ Mestverzameling}

Op een viertal melkveebedrijven is (gescheiden) mest en (gescheiden) digestaat verzameld.

- Bedrijf 1 heeft een vergistingsinstallatie (Fermtech zonder hydrolysetank) waarbij het biogas werd opgewaardeerd tot aardgaskwaliteit. De mest had een verblijftijd van circa 7 à 10 dagen in de vergister waarbij een kleine hoeveelheid (circa 3\%) glycerine werd covergist. Het digestaat werd gescheiden in een vijzelpers (Smicon, SK 100 L/4 TF).

- Bedrijf 2 heeft een vergistingsinstallatie (Biolectric) waarbij het biogas in een WKK-installatie werd omgezet in elektriciteit en warmte. De mest had een verblijftijd van circa 21 à 22 dagen in vergister. Het digestaat werd gescheiden in een vijzelpers (UTS, FSP B-52/15 Boxvulling), die specifiek gemaakt is om dikke fractie te maken voor strooisel in ligboxen en heeft daarvoor een grotere perskracht.

- Bedrijf 3 heeft een vergistingsinstallatie (HoSt Microferm) waarbij het biogas in een WKKinstallatie en een biogaskachel werd omgezet in elektriciteit en warmte. De mest had een verblijftijd van circa 30 dagen in de vergister. Het digestaat werd gescheiden in een vijzelpers (EYS, SP $600 \mathrm{HD}$ ).

- Bedrijf 4 heeft een vergistingsinstallatie (HoSt Microferm) waarbij het biogas werd opgewaardeerd tot aardgaskwaliteit. De mest werd dagelijks met een mestschuif uit de stal gehaald en naar de vergister afgevoerd. De dagverse mest had een verblijftijd van circa 27 dagen in de vergister.

De volgende onbewerkte en bewerkte runderdrijfmesten zijn op de vier bedrijven verzameld:

1. Verse runderfaeces van bedrijf 1

2. Verse runderdrijfmest (12 dagen oud), tevens gebruikt als ingaande mest van de monovergister op bedrijf 1

3. 'Oude' runderdrijfmest na 60 dagen opslag op bedrijf 1

4. Digestaat na monovergisting van bedrijf 1 , verblijftijd 7 dagen

5. Digestaat na monovergisting van bedrijf 1 , verblijftijd 7 dagen en 10 dagen uitgisting

6. Digestaat na monovergisting van bedrijf 1 , verblijftijd 7 dagen en 21 dagen uitgisting

7. Digestaat na monovergisting van bedrijf 1 , verblijftijd 7 dagen en 30 dagen uitgisting

8. Dikke fractie van gescheiden digestaat van bedrijf 1

9. Dunne fractie van gescheiden digestaat van bedrijf 1

10. Ingaande drijfmest in monovergister van bedrijf 2

11. Dikke fractie na scheiding van ingaande drijfmest van bedrijf 2

12. Dunne fractie na scheiding van ingaande drijfmest van bedrijf 2

13. Digestaat uit vergister van bedrijf 2

14. Dikke fractie na scheiding van digestaat van bedrijf 2

15. Dunne fractie na scheiding van digestaat van bedrijf 2

16. Ingaande drijfmest uit vergister van bedrijf 3

17. Digestaat uit vergister van bedrijf 3

18. Dikke fractie na scheiding van digestaat van bedrijf 3

19. Dunne fractie na scheiding van digestaat van bedrijf 3

20. Ingaande dagverse mest in vergister van bedrijf 4

21. Digestaat uit vergister van bedrijf 4

22. Digestaat uit eindopslag van bedrijf 4 


\subsection{Bemonstering mestsoorten}

\subsubsection{Bedrijf 1}

Verse runderfaeces werd verzameld door in de stal van 5 koeien de verse mestflat te bemonsteren, de submonsters werden vervolgens samengevoegd, gemengd en bemonsterd. De verse ingaande drijfmest in de monovergister werd verzameld bij een aftappunt van de vergister, net voordat de drijfmest de vergister in ging. Er werd een partij van ruim $5 \mathrm{~L}$ opgevangen in een emmer en vervolgens bemonsterd. 'Oude runderdrijfmest' werd geproduceerd door een partij van $10 \mathrm{~L}$ goed gemengde drijfmest uit de opvangput te verzamelen. Deze mest was op het moment van verzamelen 25 dagen oud. De mest werd opgeslagen in een afgesloten emmer (met enkele luchtgaatjes in het deksel) van ruim $10 \mathrm{~L}$, bij een gemiddelde buitentemperatuur van circa $7^{\circ} \mathrm{C}$ in een onverwarmde schuur. Na 35 dagen werd deze partij goed gemengd en bemonsterd. Op het moment van subbemonsteren was de mest in totaal 60 dagen in opslag geweest. Digestaat na monovergisting werd verzameld door bij een aftappunt van de monovergister een partij van ruim $7 \mathrm{~L}$ digestaat te verzamelen. Deze partij werd gemengd en bemonsterd. Op het moment van bemonsteren was de verblijftijd van het digestaat gemiddeld 7 dagen. De dikke fractie en dunne fractie van gescheiden digestaat werden geproduceerd door een partij van ruim $1000 \mathrm{~L}$ digestaat uit de vergister te scheiden met een vijzelpers en te bemonsteren. Alle monsters die verzameld waren, werden vervoerd naar Wageningen en daar ingevroren bij $-20^{\circ} \mathrm{C}$. Digestaat met oplopende verblijftijd werd geproduceerd door verlengde uitgisting in het laboratorium van LeAF. Bij de mestverzameling werd daarvoor aanvullend een partij van circa $10 \mathrm{~L}$ digestaat verzameld. Deze partij werd gemengd en vervolgens werden 9 thermosflessen van $1 \mathrm{~L}$ hiermee gevuld. Tot het moment van vullen waren de thermosflessen gevuld geweest met warm water (ca. $40^{\circ} \mathrm{C}$ ). De thermosflessen werden vervoerd naar het LeAF-laboratorium in Wageningen, de inhoud werd gemengd tot een mengmonster, de temperatuur werd gemeten $\left(32^{\circ} \mathrm{C}\right)$ en vervolgens werd de restgasbepaling ingezet.

\subsubsection{Bedrijf 2}

De dikke fractie en dunne fractie van ingaande drijfmest in de monovergister werden verzameld uit het lopende scheidingsproces. Scheiding vond plaats met een vijzelpers. Van de dunne fractie werd een hoeveelheid van ruim $5 \mathrm{~L}$ verzameld uit de lopende afvoer naar de mestsilo. Deze hoeveelheid werd gemengd en bemonsterd. Van de dikke fractie werd een aantal kilogram verzameld, gemengd, en bemonsterd. Na het verzamelen van de monsters van de ingaande drijfmest werd een kraan in de mestaanvoer naar de scheider omgezet, waarna 20 minuten lang digestaat werd gescheiden in dikke fractie en dunne fractie. Na 10-15 minuten wachten werden deze op dezelfde manier verzameld als bij de ingaande mest. Daarna werd de mestmixer onder de roosters van de stal aangezet en werd de drijfmest intensief gemixed. Met een multisampler (lengte 1,8 m; diameter $35 \mathrm{~mm}$ ) (Eijkelkamp, Giesbeek) werd tussen de roosters door een hoeveelheid ingaande drijfmest verzameld. Deze hoeveelheid werd gemengd en bemonsterd. Van het digestaat werd een hoeveelheid van ruim $5 \mathrm{~L}$ afgetapt van een aftappunt direct bij de vergister. Deze hoeveelheid werd gemengd en bemonsterd. Alle monsters werden vervolgens vervoerd naar Wageningen en daar ingevroren bij $-20^{\circ} \mathrm{C}$.

\subsubsection{Bedrijf 3}

Van de ingaande drijfmest in de monovergister werd een partij van $10 \mathrm{~L}$ verzameld, goed gemengd en vervolgens bemonsterd. Van het digestaat werd eveneens een partij van $10 \mathrm{~L}$ verzameld, goed gemengd, en vervolgens bemonsterd. Een partij digestaat werd gescheiden met de vijzelpers en vervolgens werden de dikke fractie en dunne fractie bemonsterd. Alle monsters werden vervolgens vervoerd naar Wageningen en daar ingevroren bij $-20^{\circ} \mathrm{C}$.

\subsubsection{Bedrijf 4}

Van de ingaande dagverse drijfmest in de monovergister werd een partij van $10 \mathrm{~L}$ verzameld, goed gemengd en vervolgens bemonsterd. Van het digestaat werd eveneens een partij van $10 \mathrm{~L}$ verzameld, goed gemengd, en vervolgens bemonsterd. Uit de eindopslag van de digestaat werd een partij van 10 
$L$ verzameld, goed gemengd en vervolgens bemonsterd. Alle monsters werden vervolgens vervoerd naar Wageningen en daar ingevroren bij $-20^{\circ} \mathrm{C}$.

\subsection{Mestanalyses}

De onbewerkte en bewerkte runderdrijfmesten zijn geanalyseerd op de volgende kenmerken:

- $\quad$ Droge stof gehalte (drogen bij $105 \stackrel{\circ}{\circ}$ C) (NEN 7432)

- $\quad$ Organische stof (o.b.v. gloeiverlies) (NEN 7432)

- Totaal-N (NEN 7434)

- $\quad$ Ammonium-N (NEN 7438)

- Totaal-P uitgedrukt als $\mathrm{P}_{2} \mathrm{O}_{5}$ (NEN 7435)

- $\quad$ Orthofosfaat (NEN 6479)

- $\quad$ Calcium (ICP-bepaling na destructie met $\mathrm{HCL} / \mathrm{HNO}_{3}$ )

- Magnesium (ICP-bepaling na destructie met $\mathrm{HCL} / \mathrm{HNO}_{3}$ )

In dit onderzoek zijn de volgende drie groepen fosfaatvormen onderscheiden:

- Orthofosfaat (i.e. het daadwerkelijk opgeloste orthofosfaat $\left(\mathrm{PO}_{4}{ }^{3-}, \mathrm{HPO}_{4}{ }^{2-}\right.$, etc.),

- Mineraal fosfaat (o.a. calciumfosfaat, struviet),

- Organisch fosfaat (o.a. fytaat, celwanden, fosfolipiden, etc.).

Het gehalte aan orthofosfaat werd als volgt bepaald:

1. Het mestmonster werd eerst gecentrifugeerd bij 4.500 rpm.

2. Het supernatant uit stap 1 werd vervolgens gecentrifugeerd bij $14.000 \mathrm{rpm}$.

3. Supernatant uit stap 2 werd $10 x$ verdund zo kort mogelijk voor de bepaling van het orthofosfaatgehalte.

4. Verdunde supernatant centrifugeren bij 14.000 rpm. Monsters werden niet gefiltreerd.

5. Vervolgens werd het fosfaat bepaald zonder destructie m.b.v. een kleuringsreactie welke specifiek is voor orthofosfaat.

\section{$2.4 \quad$ Restgasbepaling}

Om het effect van de verblijftijd (bij langere verblijftijd wordt meer organische stof afgebroken) op het gehalte aan orthofosfaat in het digestaat te bepalen zijn van bedrijf 1 vier monsters digestaat verzameld waarvan drie monsters 10, 21 en 30 dagen zijn navergist via een restgasbepaling bij LeAF in Wageningen. De restgasbepaling is ingezet op de dag van aanlevering van het digestaat. In de tabel 1 staat de karakterisering van het digestaat weergegeven.

Tabel 1 Resultaten van de karakterisering van het digestaat.

\begin{tabular}{|c|c|c|}
\hline Parameter & Gehalte & Eenheid \\
\hline $\mathrm{pH}$ & 7.8 & - \\
\hline Droge stofgehalte (DS) & 73.9 & $\mathrm{~g} / \mathrm{kg}$ \\
\hline$\%$ OS van DS & 75 & $\%$ \\
\hline Vluchtige vetzuren & 1720 & $\mathrm{mg} \mathrm{CZV/l}$ \\
\hline Acetaat & 1470 & $\mathrm{mg} / \mathrm{l}$ \\
\hline Valeraat & $<20$ & $\mathrm{mg} / \mathrm{l}$ \\
\hline
\end{tabular}

De restgasbepaling test is uitgevoerd in 9 twee-liter flessen. Per fles is $750 \mathrm{~g}$ monster (natgewicht) ingewogen. Het organische stofgehalte in alle flessen kwam hiermee op ongeveer $42 \mathrm{~g}$ OS. De testen zijn uitgevoerd bij $36^{\circ} \mathrm{C}$ en alle flessen werden op werkdagen dagelijks handmatig geschud. Voor aanvang van de testen is de gasfase van alle flessen vervangen door stikstofgas. Tijdens de test is de gasproductie gemeten. Aan het eind van elke test zijn de biogassamenstelling, $\mathrm{pH}$, droge en organische stofgehalte, en het gehalte vluchtige vetzuren bepaald. De eerste drie flessen werden gestopt na 10 dagen, de volgende drie na 21 dagen en de laatste drie na 30 dagen incubatie. 
De analyses zijn als volgt uitgevoerd. De $\mathrm{pH}$ is gemeten met een dagelijks gekalibreerde pH-elektrode. Het gehalte aan vluchtige vetzuren van de opgeloste fractie werd gaschromatografisch bepaald. De voorbewerking van de monsters bestond uit het verdunnen van het substraat, tien minuten centrifugeren bij 10000 rpm, en verdunning van het supernatant met 3\% mierenzuur. Deze analyse betreft vluchtige vetzuren met een ketenlengte van $2 \mathrm{t} / \mathrm{m} 5$ koolstofatomen (azijnzuur, propionzuur, boterzuur en valeriaanzuur). De detectielimiet was voor elk vetzuur $20 \mathrm{mg} / \mathrm{l}$. Het volume geproduceerd biogas werd bepaald met behulp van een drukmeetsysteem. De gehaltes methaan, koolstofdioxide en waterstof in het biogas werden gaschromatografisch bepaald. De detectielimiet voor waterstof was $0.02 \%$. Het gehalte droge stof en organische stof werd bepaald volgens de standaardmethode, met droging van de monsters bij $105^{\circ} \mathrm{C}$ en verassing bij $550^{\circ} \mathrm{C}$.

\subsection{Terugwinning van fosfaat uit de dunne fractie}

In aanvulling op de bepaling van het gehalte aan orthofosfaat in de dunne fractie is getracht het orthofosfaat uit de dunne fractie te winnen door dosering van calciumhydroxide $\left(\mathrm{Ca}(\mathrm{OH})_{2}\right)$. Deze methode is gebaseerd op het principe dat calcium met orthofosfaat neerslaat in de vorm van calciumfosfaat mineralen welke afgescheiden kunnen worden van de vloeistof. Het perspectief van deze methode is vooralsnog onbekend en hangt o.a. samen met het orthofosfaat gehalte in de dunne fractie. Daarnaast kan een deel van het fosfaat aanwezig zijn in de vorm van minerale colloïden (calciumfosfaat) en organische colloïden (o.a. fytaat). Het is onbekend in hoeverre colloïdale fosfaatvormen door middel van calciumhydroxide dosering teruggewonnen kunnen worden uit de dunne fractie.

's Ochtends werd in een bekerglas van $800 \mathrm{ml}$ een hoeveelheid van 500 à $600 \mathrm{ml}$ dunne fractie gedaan. Aan de dunne fracties werd een overmaat calciumhydroxide ( 2 x zoveel op mol-basis als orthofosfaat) toegevoegd om de orthofosfaat te laten neerslaan. Vervolgens werd het mengsel circa 1 uur geroerd m.b.v. een magneetroerder. Elk 30 à 60 minuten werd visueel de mate van bezinking gecontroleerd en indien mogelijk een streepje op het bekerglas gezet wat de hoogte van het bezinksel aangaf. Afhankelijk van de mate van bezinking werd de proef aan het eind van de dag beëindigd of de volgende ochtend. Na bezinking werd het supernatant gescheiden van het sediment d.m.v.

centrifugeren. De ingaande dunne fractie, het centrifugaat en sediment zijn gewogen en geanalyseerd op: drogestof, fosfaat, orthofosfaat en $\mathrm{pH}$. Bij de uitvoering is geen controle behandeling meegenomen zonder calciumhydroxide dosering. 


\section{Resultaten}

\subsection{Invloed opslagduur}

In tabel 2 staan de analyseresultaten van de mesten van bedrijven 1 en 4 met verschillende opslagduur weergegeven.

Tabel 2 Analyseresultaten van de mesten van bedrijf 1 en 4 met verschillende opslagduur.

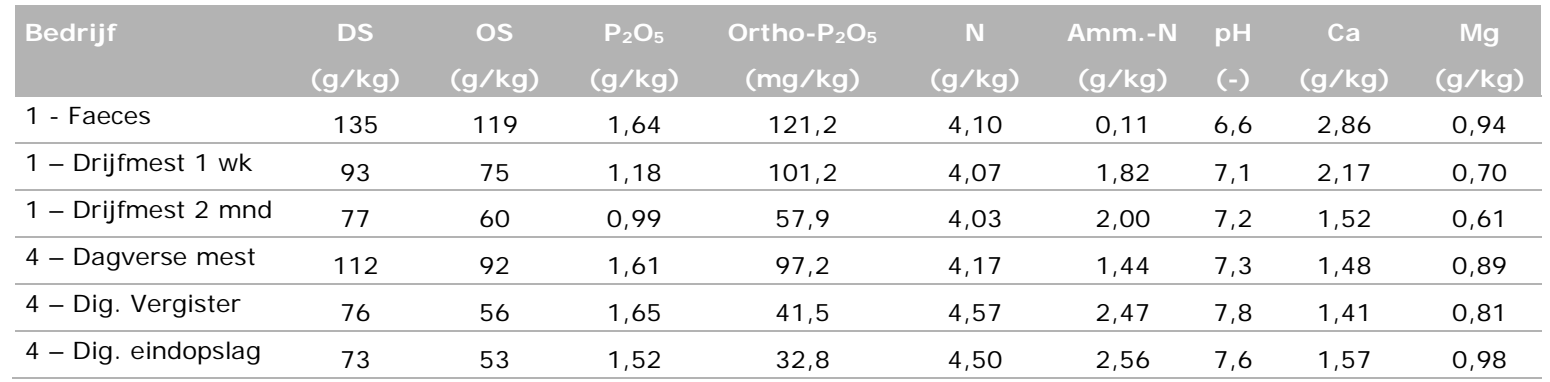

Het blijkt dat de faeces het hoogste droge stof en organische stof gehalte heeft. Tevens heeft de faeces veruit het laagste ammoniumgehalte met $0,11 \mathrm{~g} / \mathrm{kg}$, omdat de omzetting van ureumstikstof naar ammoniak nog vrijwel niet heeft plaatsgevonden in verse faeces. Daardoor is de $\mathrm{pH}$ beduidend lager dan van de drijfmesten en dagverse mest. Het fosfaatgehalte in de mesten varieerde van 0,99 tot $1,65 \mathrm{~g} / \mathrm{kg}$. Het orthofosfaat-gehalte varieerde van 32,8 tot $121,2 \mathrm{mg} / \mathrm{kg}$. Het aandeel van orthofosfaat in het totaal fosfaatgehalte varieerde van 2,2 tot 8,6\%. In figuren 1, 2 en 3 staat het orthofosfaat gehalte in relatie tot het fosfaatgehalte, de $\mathrm{pH}$, calcium- en magnesiumgehalte weergegeven.

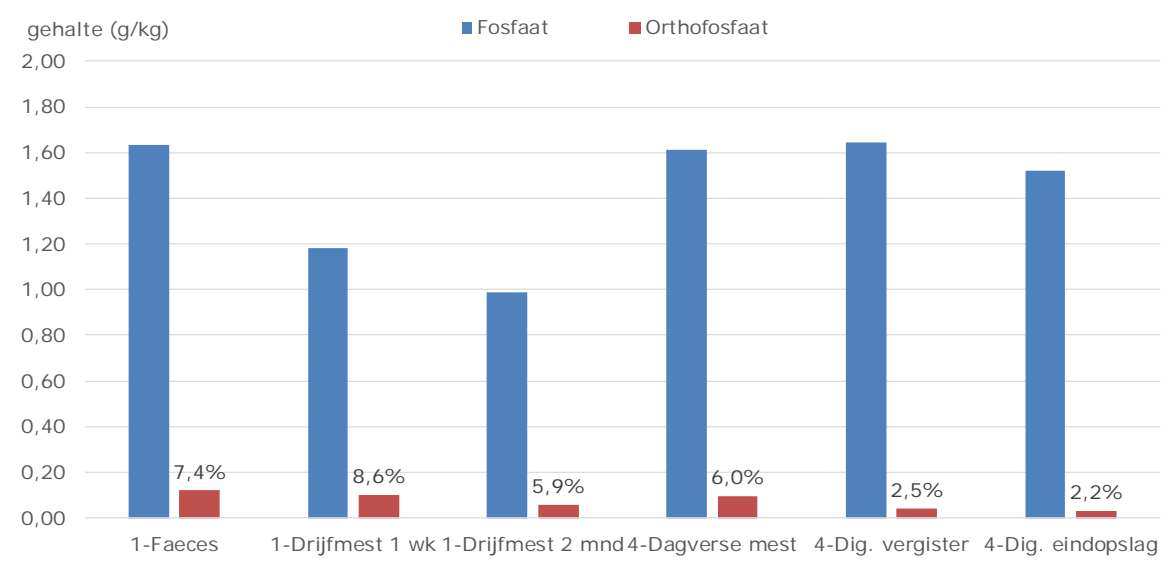

Figuur 1 Fosfaat en orthofosfaat gehalten van de mesten van bedrijven 1 en 4 met verschillende opslagduur met het aandeel orthofosfaat in het totaal fosfaatgehalte.

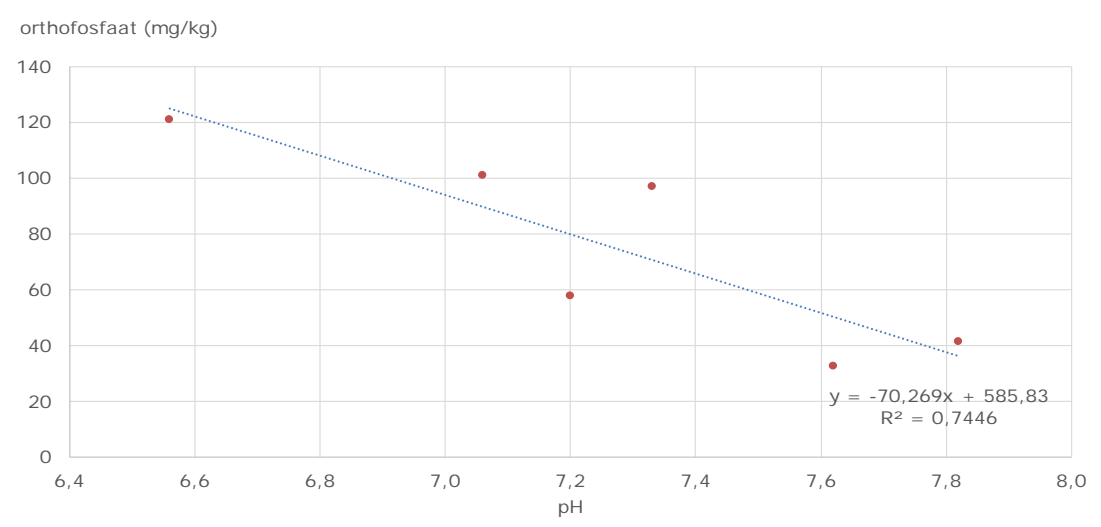

Figuur 2 Orthofostaat gehalte in relatie tot de $\mathrm{pH}$ van de mesten van bedrijven 1 en 4 met verschillende opslagduur. 


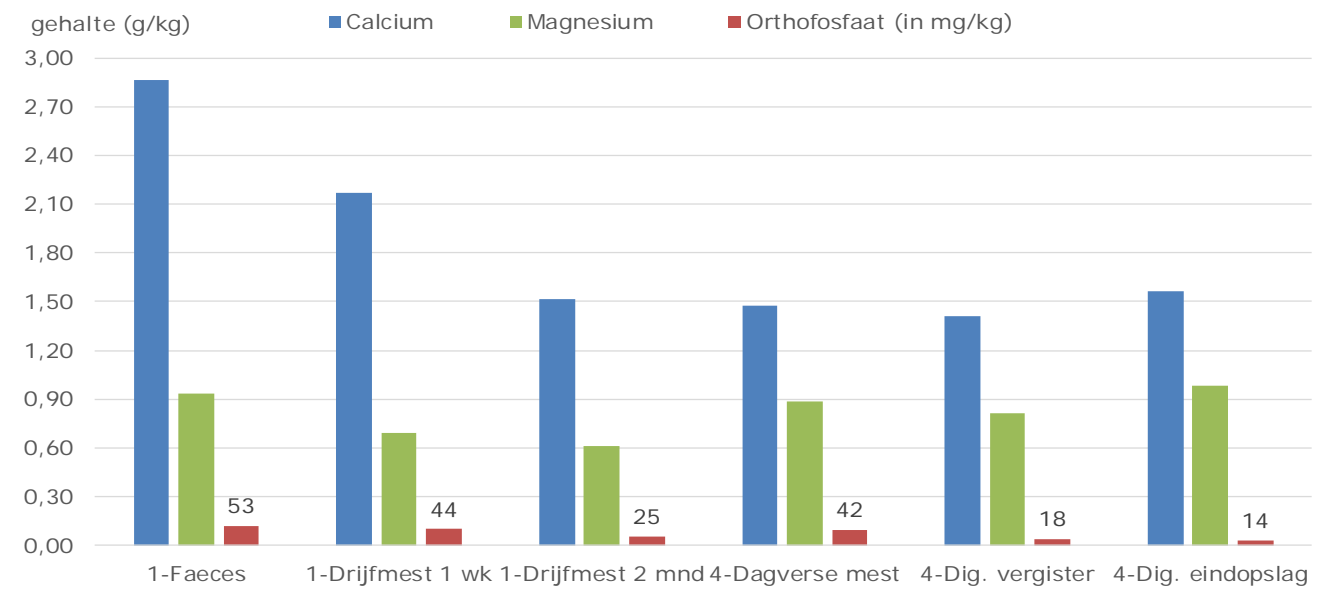

Figuur 3 Orthofosfaat, calcium- en magnesiumgehalten van de mesten van bedrijven 1 en 4 met verschillende opslagduur.

Bij zowel bedrijf 1 als bedrijf 4 is het orthofosfaat gehalte het laagst in de oudste mest. Hoewel het maar om twee bedrijven gaat, lijkt het erop te wijzen dat door de afbraak van de organische stof in de opslag mineralen vrijkomen en/of door een hogere $\mathrm{pH}$ meer orthofosfaat wordt gebonden en kan neerslaan. Dit lijkt ondersteund te worden doordat de oudste mest ook het laagste fosfaatgehalte bevat wat erop kan duiden dat een deel van het fosfaat is neergeslagen in de kelder en dat er goed verband lijkt te zijn tussen de $\mathrm{pH}$ en het orthofosfaat gehalte. Bij bedrijf 1 nemen ook het calcium- en magnesiumgehalte af naarmate de mest langer in opslag is, welke o.a. gereageerd kunnen hebben met orthofosfaat en zijn neergeslagen. Echter dit is niet het geval voor bedrijf 4 waar de calcium- en magnesiumgehalten niet veel van elkaar verschillen naarmate de opslagduur langer was. In de vergister zou dit veroorzaakt kunnen zijn doordat het digestaat in de vergistingstank meerder keren per dag wordt gemixt. Daarentegen is het calciumgehalte in de mesten van bedrijf 4 vergelijkbaar met de oudste mest van bedrijf 1 wat erop kan duiden dat bedrijf 1 een hoger calciumgebruik heeft in het voer en/of de ligboxen. De analyseresultaten wijzen erop dat verse mest het hoogste orthofosfaat heeft en hoe langer de mest in opslag blijft hoe lager het orthofosfaat-gehalte wordt.

\subsection{Effect van vergisting en vergistingsduur}

In tabel 3 staan de analyseresultaten van het effect van vergisting op de gehalten in de mesten van de vier bedrijven weergegeven.

Tabel 3 Analyseresultaten van de ingaande mest en digestaat van de bedrijven met een scheider

\begin{tabular}{|c|c|c|c|c|c|c|c|c|c|c|}
\hline \multirow[t]{2}{*}{ Bedrijf } & \multirow{2}{*}{$\begin{array}{c}\text { DS } \\
(\mathrm{g} / \mathrm{kg})\end{array}$} & \multirow{2}{*}{$\begin{array}{c}\text { Os } \\
(\mathrm{g} / \mathrm{kg})\end{array}$} & \multirow{2}{*}{$\begin{array}{l}\mathrm{P}_{2} \mathrm{O}_{5} \\
(\mathrm{~g} / \mathrm{kg})\end{array}$} & \multirow{2}{*}{$\begin{array}{l}\text { Ortho- } \mathrm{P}_{2} \mathrm{O}_{5} \\
(\mathrm{mg} / \mathrm{kg})\end{array}$} & \multirow{2}{*}{$\begin{array}{c}N \\
(g / k g)\end{array}$} & \multicolumn{2}{|c|}{ Amm.-N } & \multirow{2}{*}{$\begin{array}{l}\mathrm{pH} \\
(-)\end{array}$} & \multirow{2}{*}{$\begin{array}{c}\mathrm{Ca} \\
(\mathrm{g} / \mathrm{kg})\end{array}$} & \multirow{2}{*}{$\begin{array}{c}M g \\
(\mathrm{~g} / \mathrm{kg})\end{array}$} \\
\hline & & & & & & $(\mathrm{g} / \mathrm{kg})$ & $(\%)$ & & & \\
\hline 1 - Drijfmest 1 wk & 93 & 75 & 1,18 & 101,2 & 4,07 & 1,82 & $45 \%$ & 7,1 & 2,17 & 0,70 \\
\hline 1 - Digestaat & 71 & 53 & 1,05 & 59,4 & 3,98 & 1,76 & $44 \%$ & 7,6 & 1,70 & 0,64 \\
\hline 2 - Drijfmest & 92 & 67 & 1,63 & 45,9 & 4,73 & 2,29 & $48 \%$ & 7,8 & 2,51 & 1,17 \\
\hline 2 - Digestaat & 78 & 55 & 1,63 & 22,9 & 4,84 & 2,66 & $55 \%$ & 8,0 & 2,39 & 1,15 \\
\hline 3 - Drijfmest & 88 & 69 & 1,46 & 57,4 & 4,55 & 1,88 & $41 \%$ & 7,6 & 2,16 & 1,08 \\
\hline 3 - Digestaat & 46 & 31 & 1,04 & 13,2 & 4,42 & 2,77 & $63 \%$ & 8,0 & 1,38 & 0,79 \\
\hline 4 - Dagverse mest & 112 & 92 & 1,61 & 97,2 & 4,17 & 1,44 & $35 \%$ & 7,3 & 1,48 & 0,89 \\
\hline 4 - Dig. Vergister & 76 & 56 & 1,65 & 41,5 & 4,57 & 2,47 & $54 \%$ & 7,8 & 1,41 & 0,81 \\
\hline
\end{tabular}


Zoals verwacht neemt op alle bedrijven het organische en drogestofgehalte af als gevolg van de omzetting van organische stof in biogas. Het effect op het fosfaat- en stikstofgehalte is wisselend, maar het ammoniumgehalte neemt bij drie van de vier vergisters toe, alleen niet voor bedrijf 1 wat mogelijk veroorzaakt is door de korte verblijftijd van 7 dagen in de vergister. Het fosfaatgehalte in de mesten varieerde van 1,04 tot $1,65 \mathrm{~g} / \mathrm{kg}$. Het orthofosfaat gehalte varieerde van 13,2 tot 101,2 $\mathrm{mg} / \mathrm{kg}$. Het aandeel van orthofosfaat in het totaal fosfaatgehalte varieerde van 1,3 tot $8,6 \%$. In figuren 4, 5 en 6 staat het orthofosfaat-gehalte in relatie tot het fosfaatgehalte, $\mathrm{pH}$ en het calcium- en magnesiumgehalte weergegeven.

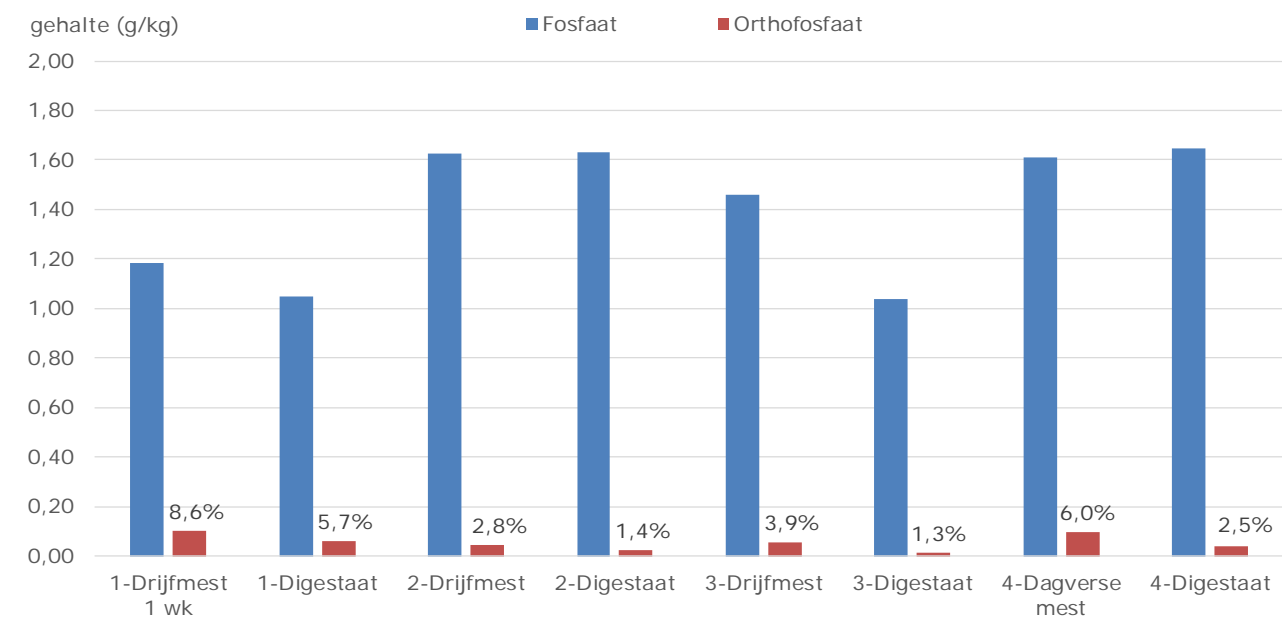

Figuur 4 Fosfaat en orthofosfaat gehalten van de drijfmest en digestaat van bedrijven 1, 2, 3 en 4 met het aandeel orthofosfaat in het totaal fosfaatgehalte.

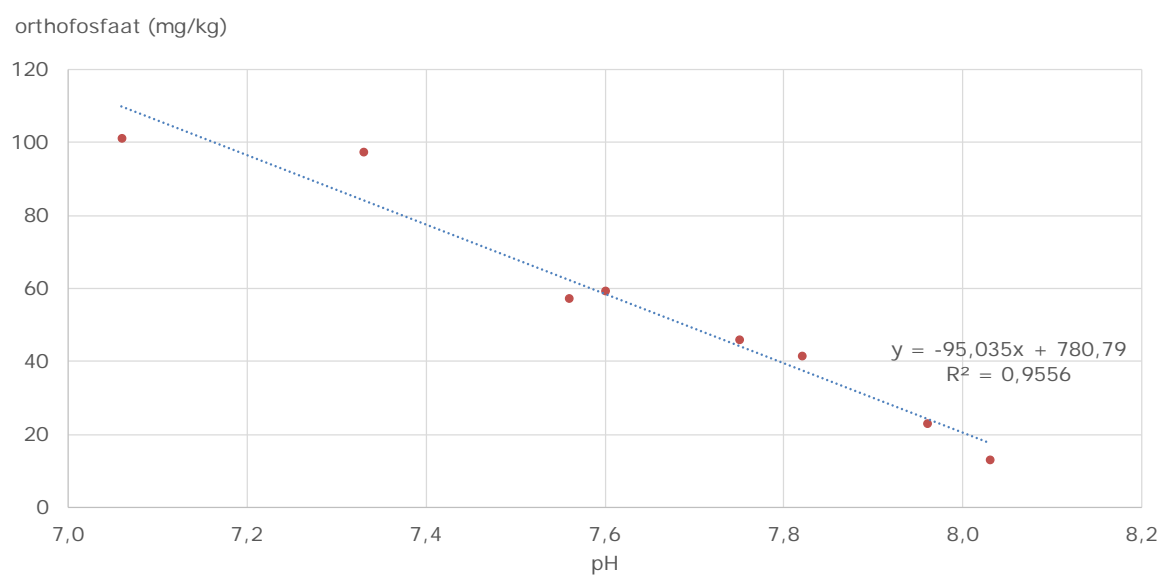

Figuur 5 Orthofosfaat gehalte in relatie tot de $\mathrm{pH}$ van de drijfmest en digestaat van bedrijven 1,2 , 3 en 4.

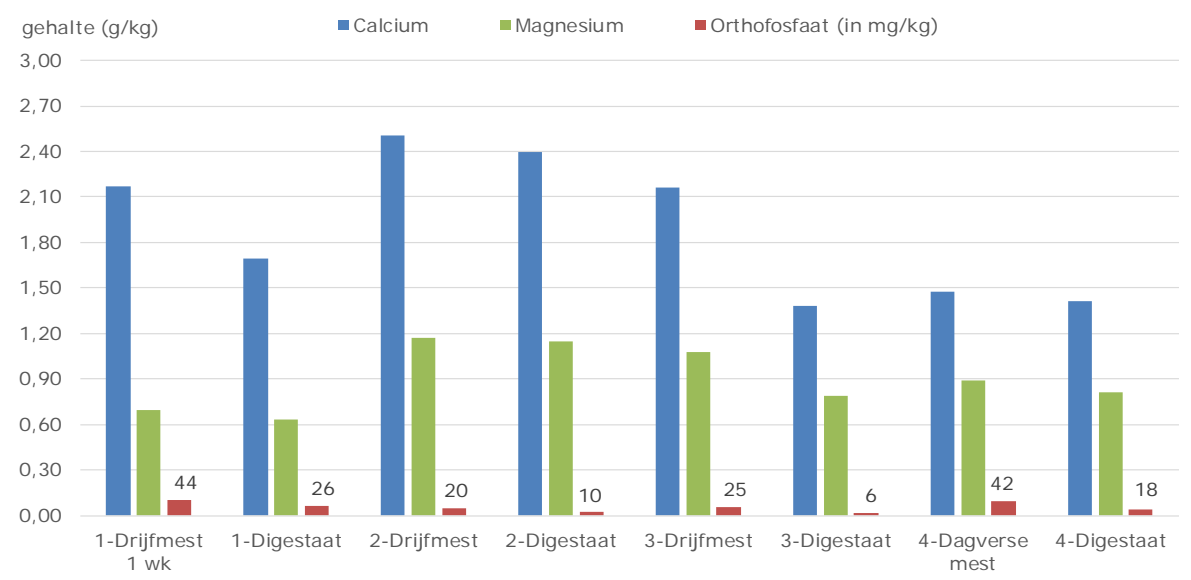

Figuur 6 Orthofosfaat-, calcium- en magnesiumgehalte van de drijfmest en digestaat van bedrijven $1,2,3$ en 4 . 
Wat opvalt is dat bij bedrijven 1 en 3 het digestaat een beduidend lager fosfaatgehalte heeft dan de drijfmest terwijl bij bedrijven 2 en 4 het fosfaatgehalte nagenoeg gelijk is bij de drijfmest en het digestaat. Dit geldt ook voor het calciumgehalte en in mindere mate voor het magnesiumgehalte. In alle gevallen is het orthofosfaat gehalte lager in het digestaat dan in de ingaande drijfmest. Het gehalte neemt met meer dan $40 \%$ af. De analyseresultaten wijzen erop dat door vergisting het orthofosfaat-gehalte lager is in het digestaat dan in de ingaande drijfmest.

In tabel 4 staan de analyseresultaten van het effect van een langere vergistingsduur (verblijftijd) op de gehalten in de mest. En in bijlage 1 staan de resultaten van de restgasbepaling weergegeven.

Tabel 4 Analyseresultaten van het digestaat uit de vergister van bedrijf 1 bij verschillende vergistingsduren.

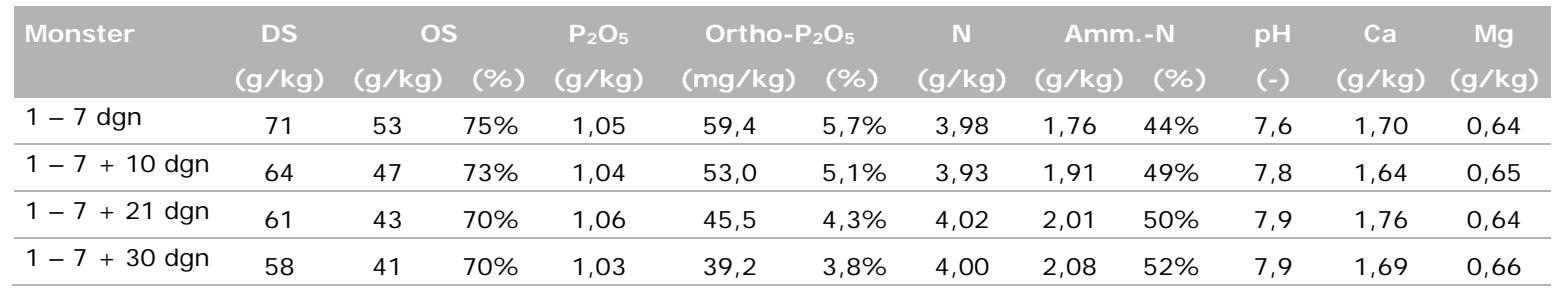

Met toenemende vergistingstijd wordt er meer organische stof omgezet in biogas waardoor het organische stofgehalte daalt en daarmee ook het drogestofgehalte. Het fosfaatgehalte schommelt rond de $1,04 \mathrm{~g} / \mathrm{kg}$. In theorie zou het fosfaatgehalte iets toe moeten nemen doordat het mestvolume wat afneemt en de hoeveelheid fosfaat niet verandert. Echter het droge stof gehalte is maar afgenomen met $1,3 \%$ ( van $7,1 \%$ naar $5,8 \%$ ) en heeft dus een geringe invloed op het totale mestvolume. Het aandeel orthofosfaat bedraagt minder dan 6\%. In figuren 7, 8 en 9 staat het orthofosfaat-gehalte in relatie tot het fosfaatgehalte, $\mathrm{pH}$ en calcium- en magnesiumgehalte weergegeven bij toenemende verblijftijd.

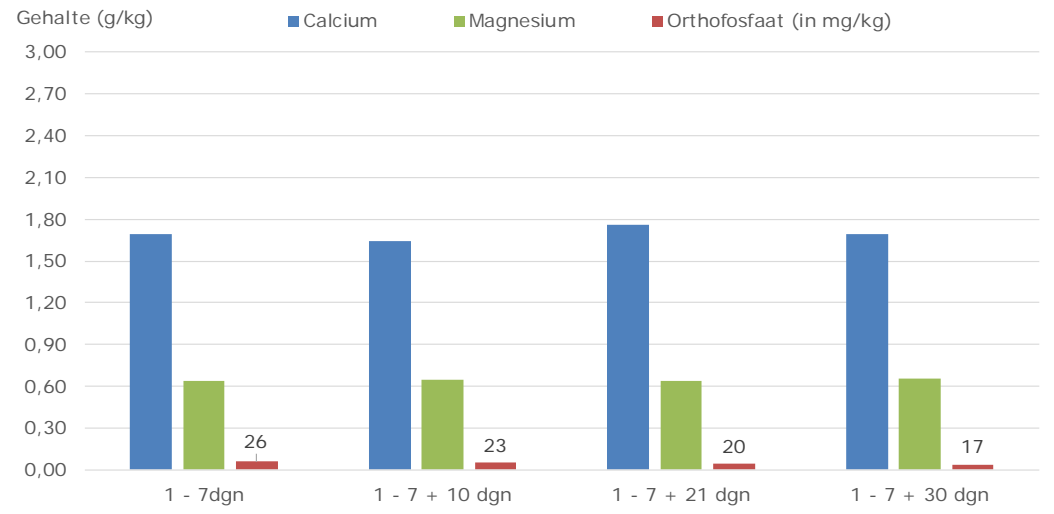

Figuur 7 Fosfaat en orthofosfaat gehalten van het digestaat van bedrijf 1 bij toenemende verblijftijd met het aandeel orthofosfaat in het totaal fosfaatgehalte.

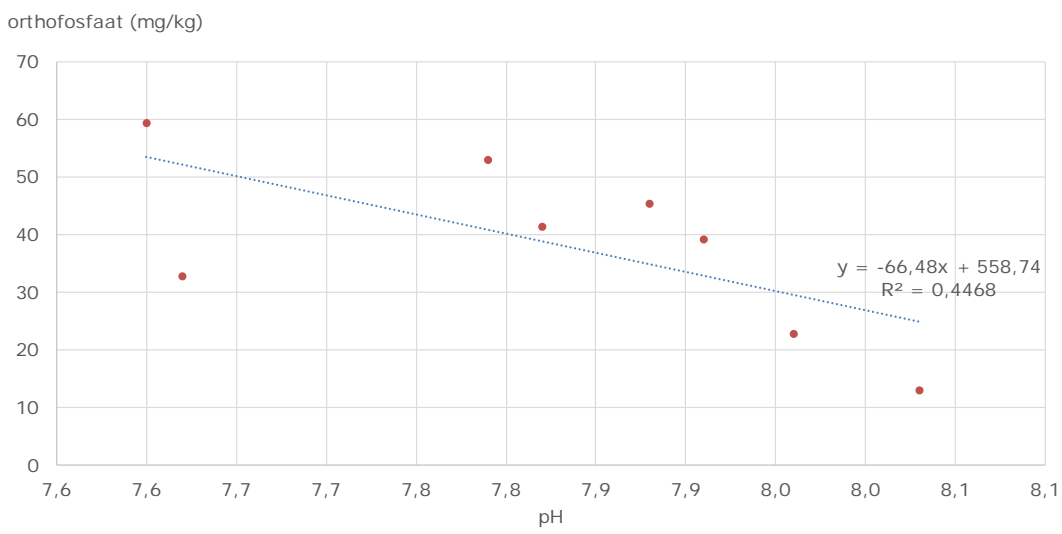

Figuur 8 Orthofosfaat gehalte in relatie tot de $\mathrm{pH}$ van het digestaat van bedrijf 1 bij toenemende verblijftijd. 


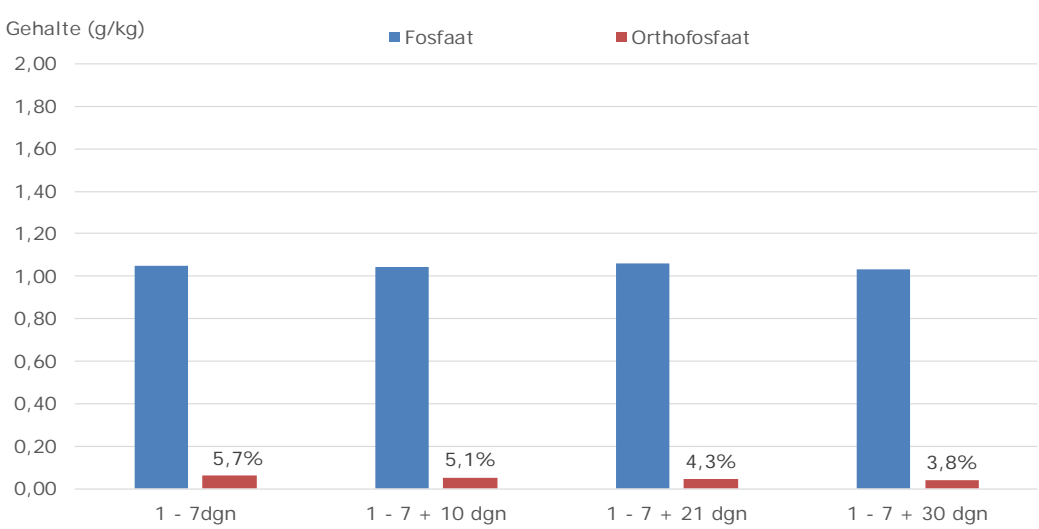

Figuur 9 Orthofosfaat-, calcium- en magnesiumgehalte van het digestaat van bedrijf 1 bij toenemende verblijftijd.

Bij toenemende verblijftijd blijkt het orthofosfaat gehalte af te nemen. De gehalten aan fosfaat, calcium en magnesium veranderden nauwelijks met toenemende verblijftijd. De analyseresultaten wijzen erop dat hoe langer de mest wordt vergist hoe lager het orthofosfaat gehalte wordt.

\subsection{Effect van scheiding op orthofosfaat}

In tabel 5 staan de analyseresultaten van het digestaat, drijfmest van bedrijf 2, de dunne en dikke fractie van de bedrijven waar drijfmest en/of digestaat is gescheiden.

Tabel 5 Analyseresultaten van de digestaat, drijfmest van bedrijf 2, dikke en dunne fracties afkomstig van digestaat en drijfmest.

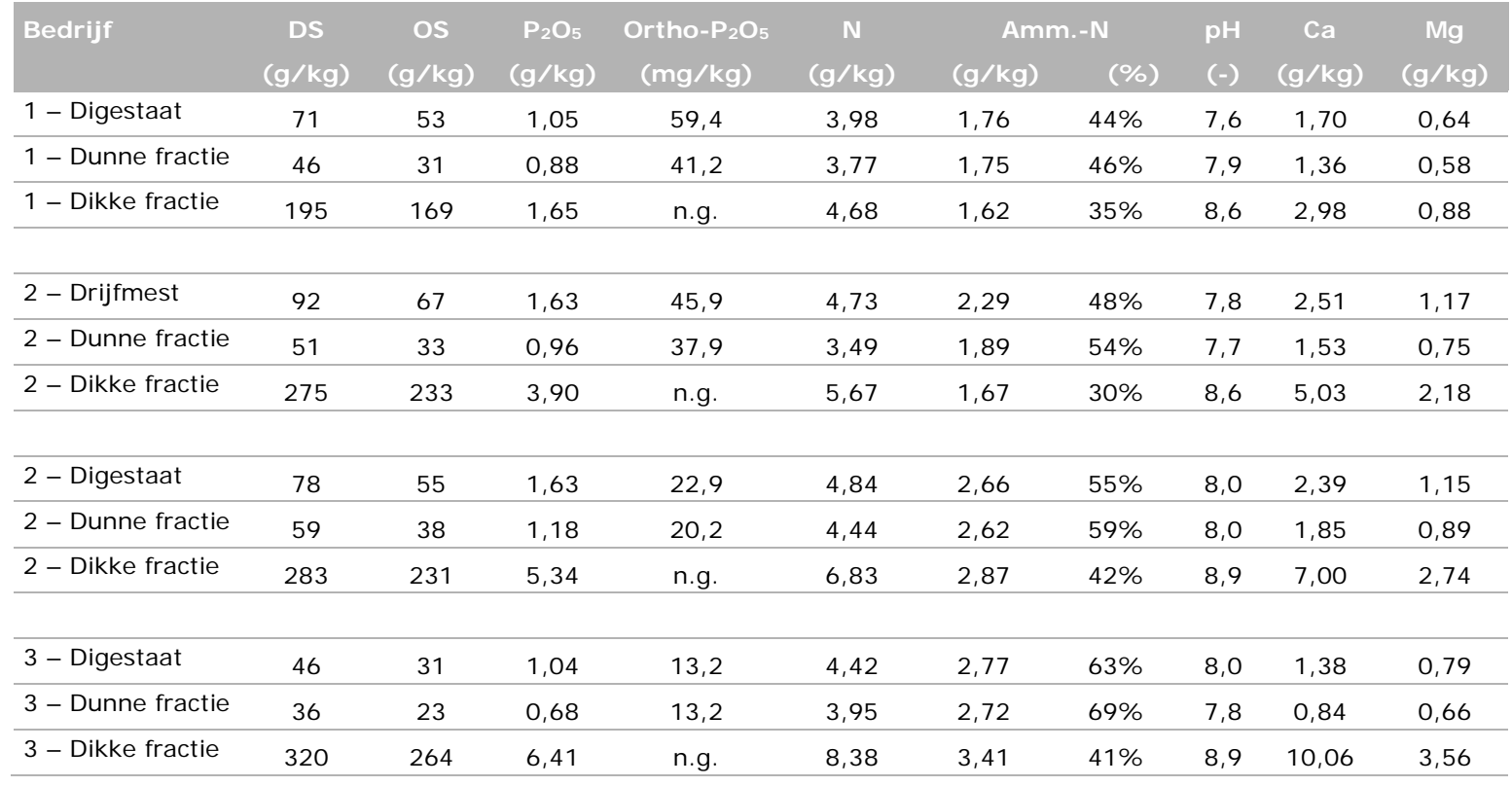

n.g. = niet gemeten, omdat het orthofosfaat-gehalte niet viel te bepalen zonder verdunning. 


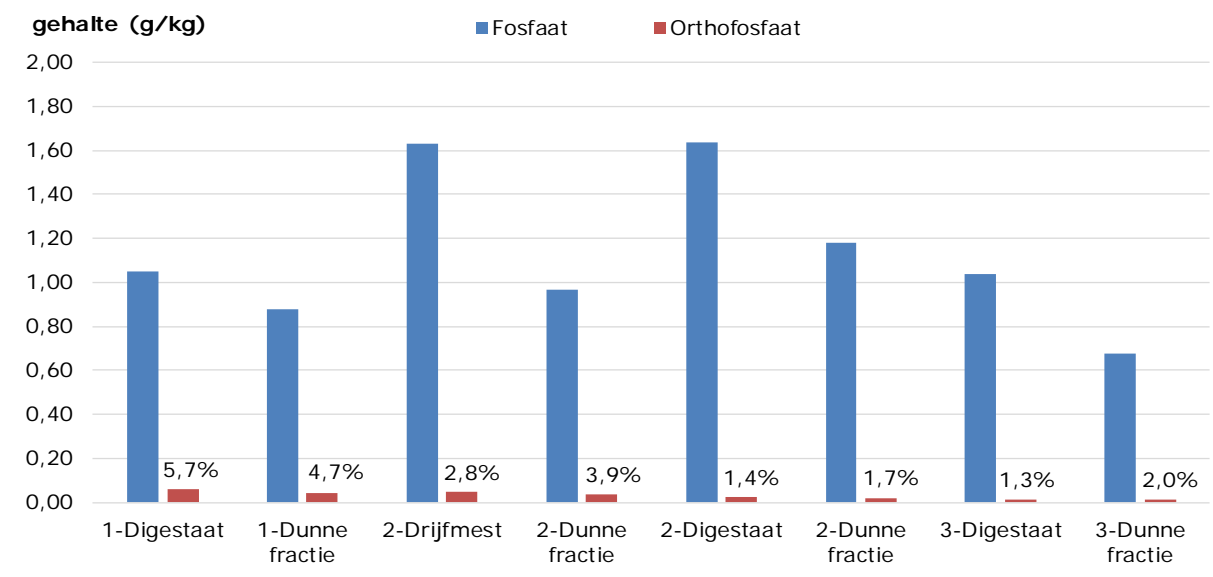

Figuur 10 Fosfaat en orthofosfaat gehalten van het digestaat/mest en de dunne fracties met het aandeel orthofosfaat in het totaal fosfaatgehalte.

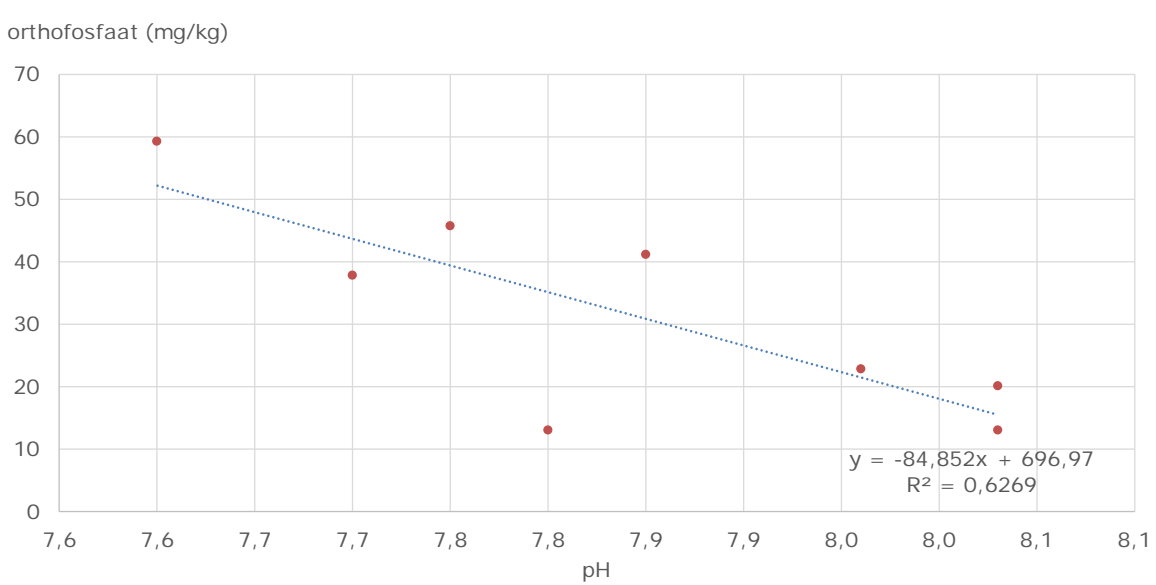

Figuur 11 Orthofosfaat gehalte in relatie tot het $\mathrm{pH}$-gehalte van de dunne fracties.

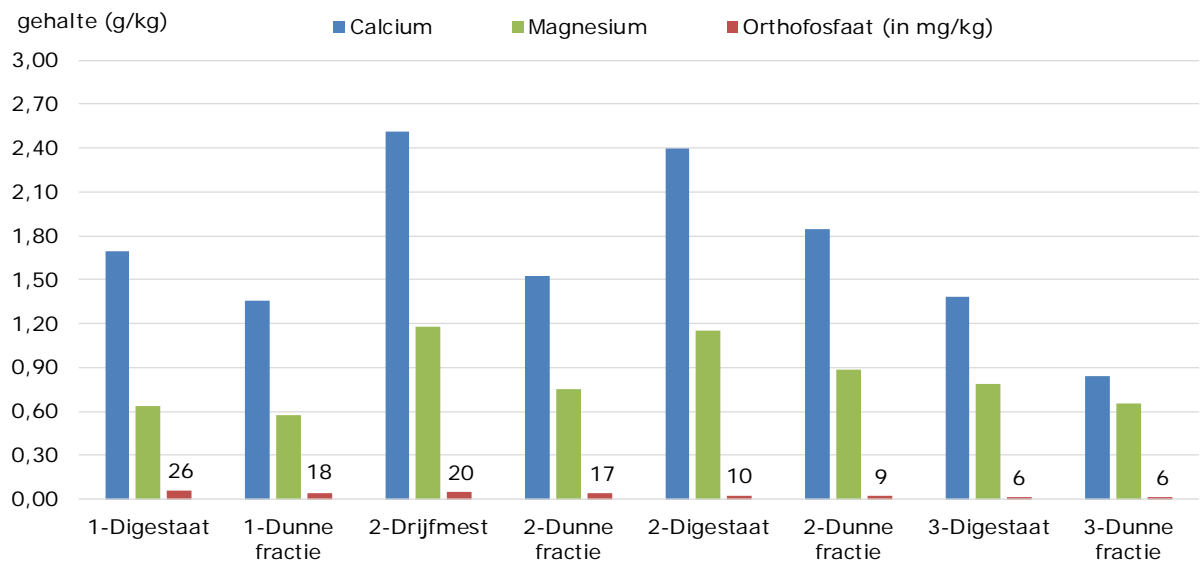

Figuur 12 Orthofosfaat-, calcium- en magnesiumgehalte van de dunne fracties.

Bij de scheiding nam het gehalte aan droge en organische stof, fosfaat en stikstof toe in de dikke fractie, terwijl dit tegelijkertijd afnam in de dunne fractie. De $\mathrm{pH}$ van de dikke fractie neemt ook toe t.o.v. de ongescheiden digestaat/mest. Bij bedrijf 2 heeft de dikke fractie digestaat hogere gehalten dan de dikke fractie drijfmest. Alleen bij bedrijf 3 blijft het orthofosfaat-gehalte gelijk in de dunne fractie, terwijl bij de andere bedrijven het orthofosfaat-gehalte in de dunne fractie afneemt t.o.v. de ingaande digestaat/mest. In figuur 10 staat het orthofosfaat gehalte in relatie tot het fosfaatgehalte weergegeven voor de ingaande digestaat/mest en dunne fractie. En in figuur 11 staat het orthofosfaat gehalte in de dunne fractie in relatie tot de $\mathrm{pH}$ weergegeven, terwijl in de figuur 12 de orthofosfaat-, calcium- en magnesiumgehalte staan weergegeven.

Procentueel neemt het orthofosfaat gehalte van het totaal fosfaatgehalte in de dunne fractie toe t.o.v. ingaande digestaat/mest, behalve bij bedrijf 1 . Met een percentage van minder $5 \%$ blijft de 
hoeveelheid orthofosfaat in het totale fosfaatgehalte laag. Daarbij is het totaal fosfaatgehalte in dunne fractie lager dan in de ingaande digestaat/mest waardoor de hoeveelheid orthofosfaat in dunne fractie gelijk of lager is dan in de ingaande digestaat/mest. Ook het calcium- en magnesiumgehalte is lager in dunne fractie. Verder lijkt er een verband te zijn tussen het $\mathrm{pH}$-gehalte en het orthofosfaat gehalte in de dunne fracties. Hoe hoger de $\mathrm{pH}$ des te lager het orthofosfaat gehalte.

\subsection{Terugwinning van orthofosfaat uit de dunne fractie}

In tabel 6 staan de resultaten van de terugwinning van orthofosfaat uit de dunne fractie door middel van het toevoegen van een overmaat aan calciumhydroxide aan de dunne fracties weergegeven.

Tabel 6 Analyseresultaten en scheidingsrendementen van de bezinkproef na toevoeging van een overmaat aan calciumhydroxide aan de dunne fracties van bedrijven 1, 2 en 3 .

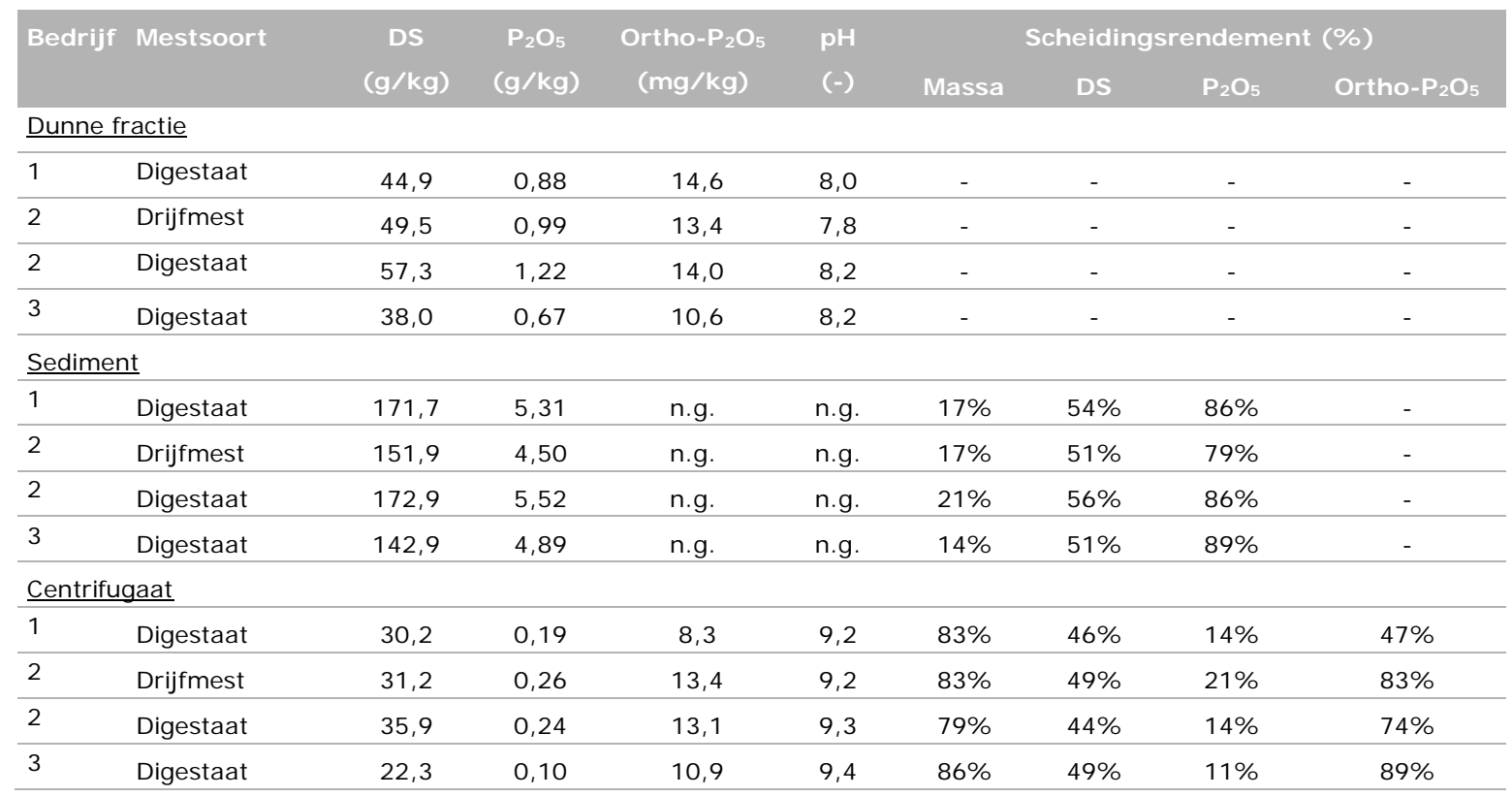

n.g. = niet gemeten .

Uit de resultaten bleek dat gemiddeld $17 \%$ van de massa en $53 \%$ van de droge stof terechtkwam in het sediment. De toevoeging van calciumhydroxide heeft geleid tot lagere fosfaatgehalten in het centrifugaat en hogere fosfaatgehalten in het sediment. Gemiddeld kwam 85\% van het totale fosfaat uit de dunne fractie terecht in het sediment. Van het totale orthofosfaat uit de dunne fractie kwam gemiddeld $73 \%$ terecht in het centrifugaat en daarmee $27 \%$ in het sediment. Dit is $10 \%$ hoger dan het scheidingsrendement voor de massa wat inhoudt dat een klein deel van het beschikbare orthofosfaat gereageerd heeft met calcium en in het sediment terecht is gekomen.

Tabel 7 toont de fosfaatgehalten in de dikke fractie, dunne fractie en het sediment per kilogram product. Het fosfaatgehalte in het sediment is hoger dan in de dikke fractie met uitzondering van bedrijf 3.

Tabel 7 Fosfaatgehalten in dikke fractie, dunne fractie en het sediment verkregen na calciumhydroxide toevoeging in $\mathrm{P}_{2} \mathrm{O}_{5}$ per $\mathrm{kg}$ product en $\mathrm{kg}$ drogestof.

\begin{tabular}{llcccc} 
Bedrijf & Mestsoort & Dikke fractie & Dunne fractie & Sediment \\
& & $(\mathrm{g} / \mathrm{kg})$ & $(\mathrm{g} / \mathrm{kg})$ & 5,31 & \\
\hline 1 & Digestaat & 1,65 & 0,88 & 4,50 \\
\hline 2 & Drijfmest & 3,90 & 0,99 & 5,52 \\
\hline 3 & Digestaat & 5,34 & 1,22 & 4,89 \\
\hline
\end{tabular}




\section{Discussie}

Voor zover kon worden nagegaan zijn in internationale literatuur nauwelijks gegevens voorhanden over het effect van vergisting op het orthofosfaat gehalte in rundermest. Güngör en Karthikeyan (2008) hebben onderzoek gedaan naar het effect van vergisting op o.a. orthofosfaat en wateroplosbare fosfaat bij mest van melkkoeien. Bij 2 van de 3 stabiel draaiende vergisters was op alle drie meetmomenten het orthofosfaat lager in het digestaat dan in de ingaande mest, terwijl dit bij de derde vergister op 1 van de 3 meetmomenten het geval was. Volgens de auteurs wordt de fosfaat die gemineraliseerd is, geprecipiteerd als anorganische $\mathrm{P}$ of aan vaste deeltjes geadsorbeerd. Het gehalte aan orthofosfaat varieerde van 21 tot 96 mg $\mathrm{P}_{2} \mathrm{O}_{5}$ per liter in de ingaande mest en van circa 16 tot $44 \mathrm{mg} \mathrm{P}_{2} \mathrm{O}_{5}$ per liter in het digestaat. Het aandeel orthofosfaat was minder dan $11 \%$ van de totale fosfaat in de ingaande mest en minder dan $6 \%$ in het digestaat. Deze resultaten liggen in de range van wat in deze studie is gevonden. Verder bleek uit de studie van Güngör en Karthikeyan (2008) dat de wateroplosbare fosfaat door vergisting met 22 tot $47 \%$ afneemt tot $25-45 \%$ van het totale fosfaat wat erop wijst dat de makkelijk winbare fosfaat door vergisting afneemt. Blijkbaar is er voldoende calcium en magnesium aanwezig in het digestaat om de orthofosfaat te binden.

In de uitgevoerde studie zijn niet alle invloedsfactoren van vergisting op de beschikbaarheid van orthofosfaat onderzocht. Invloedsfactoren zoals temperatuur, effectiviteit van het vergistingsproces (i.e. afbraak van organische stof in het proces) en vastlegging van orthofosfaat door microorganismen vielen buiten de scope van deze verkennende studie en zijn van een fundamentelere aard. Gezien de resultaten van de uitgevoerde studie lijkt een nader onderzoek naar invloedsfactoren weinig zinvol, omdat bij een verdubbeling van het gehalte aan orthofosfaat er nog steeds sprake is van een relatief klein aandeel van het totale fosfaat. 


\section{Conclusies}

Uit de uitgevoerde verkennende studie naar het effect van vergisting op het orthofosfaat gehalte in rundermest zijn de volgende conclusies te trekken:

- Verse mest had met gemiddeld $107 \mathrm{mg} / \mathrm{kg}$ het hoogste orthofosfaat gehalte en hoe langer de mest in opslag bleef hoe lager het orthofosfaat gehalte werd.

- Het orthofosfaat gehalte neemt af door vergisting. Het orthofosfaat gehalte lag in het digestaat op gemiddeld $34 \mathrm{mg} / \mathrm{kg}$ en was lager dan in de ingaande drijfmest met een gemiddeld gehalte van $75 \mathrm{mg} / \mathrm{kg}$.

- $\quad$ Bij toenemende verblijftijd daalde het orthofosfaat gehalte in het digestaat, van 59 naar 39 $\mathrm{mg} / \mathrm{kg}$.

- In de dunne fracties varieerde het orthofosfaat gehalte van 13 tot $41 \mathrm{mg} / \mathrm{kg}$, en was gelijk of lager dan het orthofosfaat gehalte in de ingaande digestaat of drijfmest. Het aandeel orthofosfaat van het totaal fosfaat lag in de dunne fracties wel hoger dan in ingaande digestaat of drijfmest.

- Hoe hoger de $\mathrm{pH}$ hoe lager het gehalte aan orthofosfaat bleek te zijn in de onderzochte mestsoorten.

- Het orthofosfaat gehalte in het digestaat van vergiste rundermest, dunne en dikke fracties digestaat was niet hoog genoeg om dit te gaan winnen uit digestaat en gescheiden fracties zonder aanvullende maatregelen, zoals aanzuren om meer orthofosfaat vrij te maken uit de aanwezige minerale fosfaatverbindingen. 


\section{Literatuur}

De Boer, H.C., Timmerman, M., Verdoes, N., Schilder, H., 2018. Afbraak van organische stof uit (bewerkte) rundermest na toediening aan een zandgrond. Wageningen Livestock Research, Wageningen, The Netherlands. Rapport in voorbereiding.

Güngör, K., Karthikeyan, K.G., 2008. Phosphorus forms and extractability in dairy manure: a case study for Wisconsin on-farm anaerobic digesters. Bioresource Technology 99:425-436. 


\section{Bijlage 1 Resultaten restgasbepaling}

In tabel A staan de waarden voor de restgasproductie uit het digestaat weergegeven in $\mathrm{ml}$ per $\mathrm{g}$ substraat-OS, en het methaangehalte van het biogas. In tabel B staan de resultaten van de vloeistofanalyses.

Tabel A Samenvatting van de testresultaten met digestaat van bedrijf 1 (triplobepaling bij $36^{\circ} \mathrm{C}$ ).

\begin{tabular}{|c|c|c|c|}
\hline \multirow[t]{2}{*}{ Testperiode } & \multicolumn{2}{|c|}{ Restgasproductie } & \multirow{2}{*}{$\begin{array}{c}\mathrm{CH}_{4} \text {-gehalte } \\
\text { in het het biogas } \\
(\%)\end{array}$} \\
\hline & ( $\mathrm{m}^{3} /$ ton substraat os) & ( $m^{3} /$ ton substraat) & \\
\hline 21 dagen & $215 \pm 8$ & $11.9 \pm 0.4$ & 60 \\
\hline 30 dagen & $239 \pm 6$ & $13.3 \pm 0.3$ & 60 \\
\hline
\end{tabular}

Tabel B Resultaten van de $\mathrm{pH}$, vluchtige vetzuurbepaling, en droge en organische stofgehalte van het digestaat aan het eind van de test (gemiddelde van een triplobepaling).

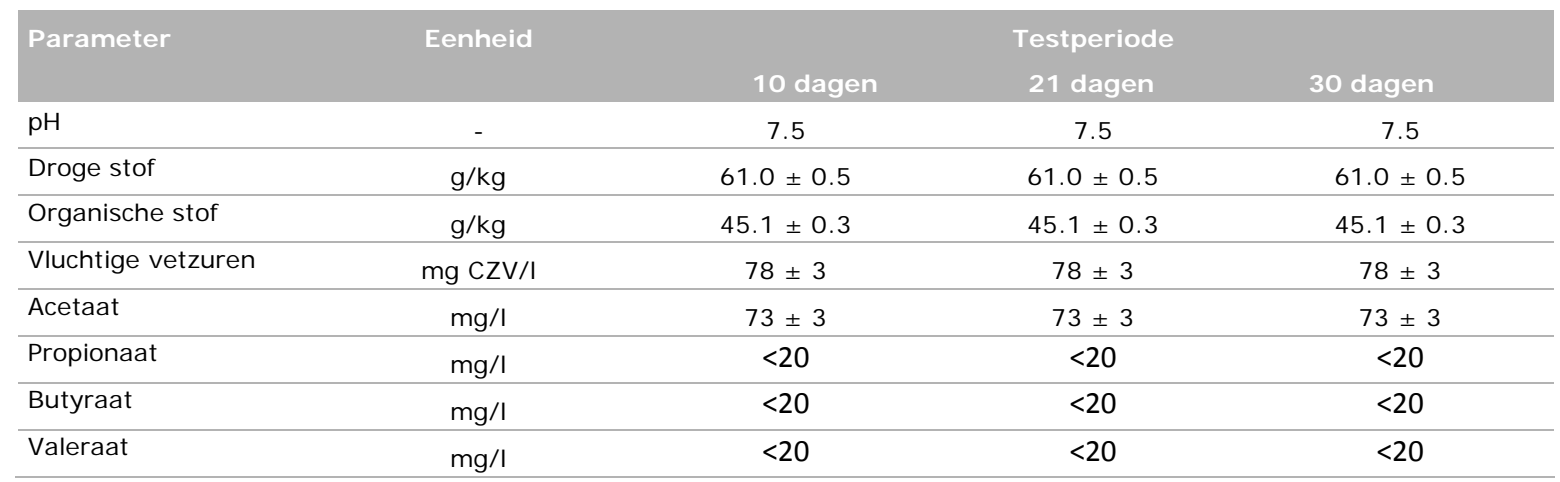




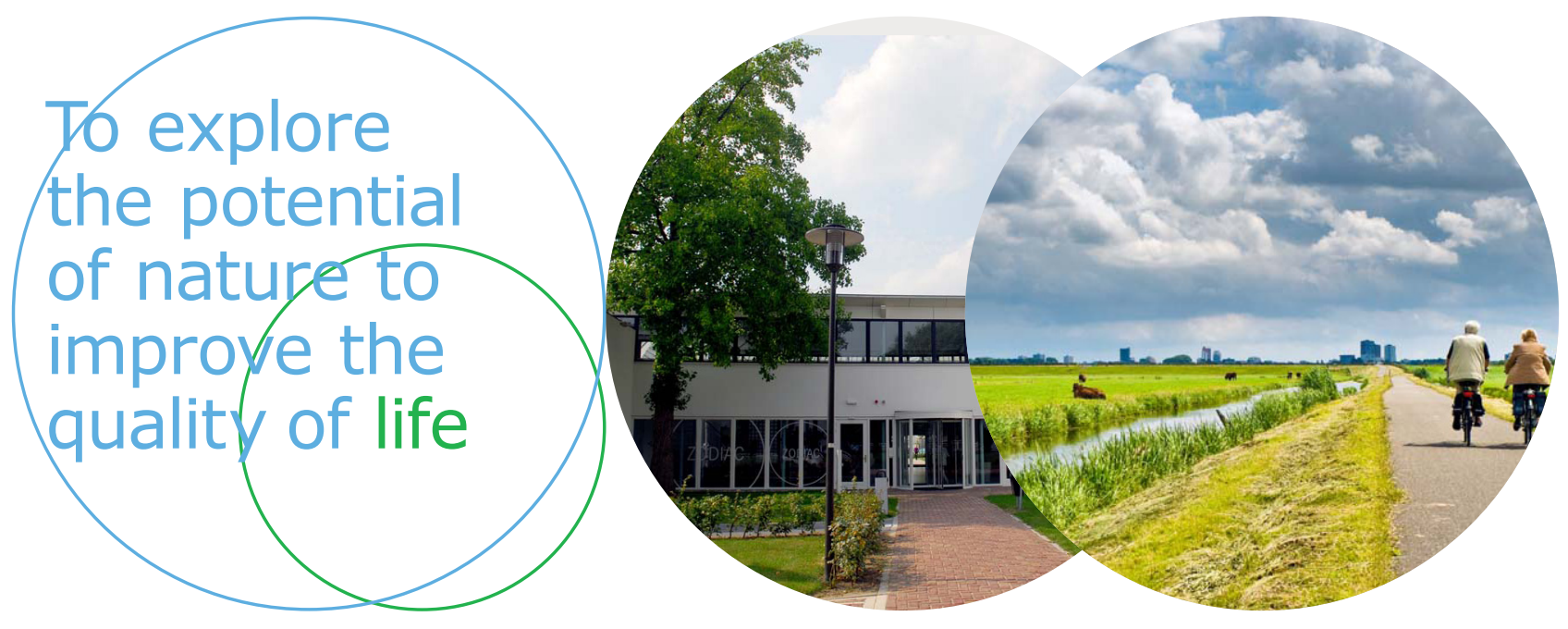

Wageningen Livestock Research Postbus 338

Wageningen Livestock Research ontwikkelt kennis voor een zorgvuldige en $6700 \mathrm{AH}$ Wageningen

T 0317483953

renderende veehouderij, vertaalt deze naar praktijkgerichte oplossingen en innovaties, en zorgt voor doorstroming van deze kennis. Onze wetenschappelijke E info.livestockresearch@wur.nl www.wur.nl/ livestock-research kennis op het gebied van veehouderijsystemen en van voeding, genetica, welzijn en milieu-impact van landbouwhuisdieren integreren we, samen met onze klanten, tot veehouderijconcepten voor de $21 \mathrm{e}$ eeuw.

De missie van Wageningen University \& Research is 'To explore the potential of nature to improve the quality of life'. Binnen Wageningen University \& Research bundelen 9 gespecialiseerde onderzoeksinstituten van Stichting Wageningen Research en Wageningen University hun krachten om bij te dragen aan de oplossing van belangrijke vragen in het domein van gezonde voeding en leefomgeving. Met ongeveer 30 vestigingen, 6.500 medewerkers en 10.000 studenten behoort Wageningen University \& Research wereldwijd tot de aansprekende kennisinstellingen binnen haar domein. De integrale benadering van de vraagstukken en de samenwerking tussen verschillende disciplines vormen het hart van de unieke Wageningen aanpak. 